\title{
Bazı Toprak Özelliklerinin Eldivan Yöresinde Yetiştirilen Kirazların Beslenme Durumu Üzerine Etkisi
}

\author{
Mustafa BAŞARAN ${ }^{1}$ \\ Mustafa OKANT ${ }^{2}$
}

Geliş Tarihi: 23.12.2003

\begin{abstract}
Öz: Bu araştırmanın amacı Eldivan yöresinde yetiştirilen kirazların makro ve mikro besin elementleri bakımından beslenme durumunun belirlenmesidir. Bu amaçla yöreyi temsilen seçilen 14 üretici bahçesinden eş zamanlı olarak toprak ve yaprak örnekleri alınmıştır. Toprak örneklerinin bazı fiziksel ve kimyasal özellikleri ile, hem toprak hem de yaprak örneklerinin $\mathrm{N}, \mathrm{P}, \mathrm{K}, \mathrm{Ca}, \mathrm{Mg}$, ve $\mathrm{Cu}, \mathrm{Fe}, \mathrm{Mn}, \mathrm{Zn}$ gibi makro ve mikro besin maddeleri kapsamları belirlenmiştir. Elde edilen sonuçlara göre araştırma alanı topraklarının nötr ve hafif alkali pH'ya, sırasıyla kumlu killi tın, killi tın ve kil bünyeye, orta derecede kireç ve düşük organik maddeye sahip olduğu belirlenmiştir. $\mathrm{N}, \mathrm{K}, \mathrm{Fe}, \mathrm{Mn}$ gibi bitki besin maddeleri toprak ve bitki örneklerinde yetersiz bulunmuştur, fakat yüksek düzeyde $\mathrm{Mg}$ ve yeterli düzeyde $\mathrm{Cu}$ ve $\mathrm{Zn}$ belirlenmiştir. Toprakların $\mathrm{Ca}, \mathrm{N}$ ve $\mathrm{Mn}$ içerikleri ile bitkilerin $\mathrm{Ca}, \mathrm{N}$ ve $\mathrm{Mn}$ içerikleri arasında önemli ilişkiler saptanmıştır $(P<0.05)$
\end{abstract}

Anahtar Kelimeler : Kiraz, beslenme durumu, Eldivan

\section{The Effects of Some Soil Properties on Nutritional Status of Cherry Grown in Eldivan District}

\begin{abstract}
This research was conducted in order to determine the nutritional status of cherry grown in Eldivan district in terms of macro and micro nutrient elements. For this purpose, both soil and leaf samples were taken from the 14 plantations of commercial cherry growers. Some chemical and physical properties of soil, and macro and micro nutrients, such as $\mathrm{N}, \mathrm{P}, \mathrm{K}, \mathrm{Ca}, \mathrm{Mg}$ and $\mathrm{Cu}, \mathrm{Fe}, \mathrm{Mn}, \mathrm{Zn}$, contents of the both soil and leaf samples were determined. According to the results, soils of the research area were neutral and slightly alkaline in $\mathrm{pH}$, sandy clay loam, clay loam, clayey in texture respectively, moderetaly in lime, and low in organic matter. Nutrients such as $\mathrm{N}, \mathrm{K}, \mathrm{Fe}, \mathrm{Mn}$ were determined as insuffucient in soil samples also in leaf samples, but $\mathrm{Mg}$ was designated at exessive and $\mathrm{Cu}, \mathrm{Zn}$ were at sufficient levels. It was determined that both soil and leaf samples were contained insufficient amounts of $\mathrm{N}, \mathrm{K}, \mathrm{Fe}$ and $\mathrm{Mn}$, but excess amount of $\mathrm{Mg}$ and sufficients amounts of $\mathrm{Cu}$ and $\mathrm{Zn}$. Important relationships were established between the soils $\mathrm{Ca}, \mathrm{N}, \mathrm{Mn}$ contents and the plants $\mathrm{Ca}, \mathrm{N}, \mathrm{Mn}$ contents.
\end{abstract}

Key Words : Cherry, nutrient status, Eldivan

\section{Giriş}

Ülkemiz nüfusunun büyük bir bölümü halen geçimini tarım sektörü ve tarıma dayalı sanayiden sağlamaktadır. Cumhuriyetin ilk yıllarından itibaren de tarım sektörü milli gelirimizde önemli bir yer tutmuştur. Özellikle meyvecilik, gittikçe artan bir ilgiye sahiptir. Son senelerde geliştirilen yüksek verim ve kaliteye sahip çeşitlerle meyveciliğimiz ve kiraz üretimimiz önemli ilerleme sağlamış ve ihraç edilen tarım ürünleri arasında ilk sıralara yerleşmeye başlamıştır. Ülkemizde 2002 yılı itibariyle 31000 ha alanda kiraz tarımı yapılmaktadır. Meyve veren ağaç sayısı 7850000 adettir. Toplam kiraz üretim miktarımız ise 2002 yılı rakamlarıyla 210000 ton olmuştur. Çankırı ilinde ise, toplam 237 ha alanda kiraz üretimi yapılmakta olup, 2002 yılı üretim 3 272 tondur. Ülkemiz kiraz ihracatı 2002 yılı itibariyle toplam 20215 ton olup, 52.5 milyon dolarlık gelir elde edilmiştir (Anonim 2002).

Toprakların olumlu ve olumsuz fiziksel ve kimyasal özellikleri, bitki besin elementlerinin azlığı veya çokluğu tarım ürünlerinin verim ve kalitesini etkileyen önemli etkenlerdendir.
Türkiye genelinde yapılan bir araştırmada; kumlu bünyeli toprakların \%53.25' inde demir noksanlığı, killi tınlı ve killi bünyedeki toprakların ise sırasıyla $\% 52.00$ ve \%51.97' sinde çinko noksanlığı görülmüştür. pH nın 7-8 arasında değiştiği topraklarda \%31 oranında demir eksikliği sorunu belirlenmiştir. Aynı şekilde yüksek pH' dan etkilenen bir diğer elementte çinkodur. $\mathrm{pH}^{\prime}$ nın 8' den yüksek olduğu topraklarda çinko eksikliği \%68.89' dur. Kireç kapsamı \%25' den fazla olan topraklarda \%45.51, organik madde miktarının ise $\% 1^{\prime}$ in altında olan topraklarda \%37.22 oranında demir eksikliği görülürken; toprakların kireç kapsamı ile yarayışlı çinko arasında bir ilişki belirlenmemiştir. Organik madde içeriği \%1' den az olan toprakların \%66.25' inde çinko eksikliği belirlenmiştir. Türkiye topraklarında bakır eksikliği sorunu bulunmamaktadır. Sadece \%0.70'inde mangan eksikliği tespit edilmiştir (Eyüboğlu ve ark. 1998). Topraklarda yüksek tuz içeriğinin ise bitki gelişimini önemli ölçüde azalttığı ve bitkide potasyum ve toplam azot miktarını düşürdüğü belirlenmiştir (Güneş ve ark. 1996). Bir çok araştırıcı toprak ve bitki analizlerini, verimlilik ve kalitenin

\footnotetext{
${ }^{1}$ Ankara Üniv. Ziraat Fakültesi Toprak Bölümü-Ankara

${ }^{2}$ Harran Üniv. Ziraat Fakültesi Tarla Bitkileri Bölümü-Şanlıurfa
} 
artırılması amacıyla, birlikte değerlendirerek, sorunlara çözüm bulmaya çalışmaktadırlar (Canözer ve ark. 1984, Köseoğlu ve Acar 1994, Köseoğlu 1995, Güleryüz ve ark. 1996, İnal ve ark. 1999, Bozkurt ve ark. 2000, Tarakçıoğlu ve ark. 2001). Bu çalışma ile Eldivan yöresinde yetiştirilen kiraz bitkisinin toprak özellikleri ile beslenme ilişkileri irdelenmiştir.

\section{Materyal ve Yöntem}

Çankırı ili Eldivan ilçesi merkezi ve yakın çevresinde yöreyi temsilen kiraz üreticileri bahçelerinden seçilen 14 ayrı bahçede 2003 yılının haziran ayında $0-30 \mathrm{~cm}$ ve $30-$ $60 \mathrm{~cm}$ derinliklerden bahçeyi temsil edecek şekilde, toprak ve toprakların alındığı bahçelerdeki kiraz ağaçlarından yaprak örneği alınmıştır. Toprak örnekleri bez torbalarla laboratuvara nakledilmiş, hava kuru hale getirildikten sonra, 2'mm lik elekten geçirilerek cam kavanozlar da muhafaza edilmişlerdir. Yaprak örneği alınırken, yapraklarındaki besin elementi miktarlarında farklılıklar olmadığı için, anaç ve çeşit ayırımı yapılmamıştır (Canözer ve ark. 1984). Örnekler, herhangi bir araz içermeyen genç sürgünlerin orta yapraklarından yeteri kadar alınıp en kısa sürede laboratuvara nakledilmiş, saf su ile yıkanmış, $65{ }^{\circ} \mathrm{C}$ 'de fırında kurutularak öğütülmüş ve analize hazırlanmıştır.

Topraklarda tekstür analizi Bouyoucos'e göre, toprak reaksionu 1:2.5 toprak su karışımında Jackson'a göre, kireç Çağlar'a göre, organik madde modifiye edilmiş Walkley-Black yaş yakma yöntemine göre, toplam $N$ Bremner ve bitkiye yarayışlı $P$ Olsen ve arkadaşlarına göre, değişebilir $\mathrm{K}$ ve $\mathrm{Na}$ Pratt, değişebilir $\mathrm{Ca}$ ve $\mathrm{Mg}$ Jackson'a göre, bitkiye yarayışlı $\mathrm{Fe}, \mathrm{Cu}, \mathrm{Zn}, \mathrm{Mn}$ Lindsay ve Norvell'e göre, Kacar' In (1994) bildirdiği şekilde belirlenmiştir.

Bitkide P Kitson ve Mellon'e göre Spectronic 20D de spektrofotometrik yöntemle, toplam N Bremner'e göre, Kjeldahl yöntemine (Kjeltec Auto 1030) göre, K ve Na Kacar'a göre, Jenway Flame Photometrede yaş yakma yöntemiyle yapılmıştır. $\mathrm{Ca}, \mathrm{Mg}, \mathrm{Fe}, \mathrm{Cu}, \mathrm{Zn}, \mathrm{Mn}$, Kacar (1972)'ın bildirdiği şekilde Atomik Absorbsiyon Spektrofotometresiyle (Perkin-Elmer 3110) tespit edilmiştir.

\section{Bulgular ve Tartışma}

Toprakların bazı fiziksel ve kimyasal özellikleri: Lindsay ve Norvell (1969), FAO (1990), TOVEP (1991), Güneş ve ark. (1996)'ya göre Alpaslan ve ark. (1998)'in bildirdiği şekilde Çizelge 1' de verilmiş olan toprak analizleri açısından incelendiğinde araştırma yöresi topraklarının pH'sının nötr den hafif alkaline doğru değiştiği görülmektedir. Topraklarda $\mathrm{pH}$ en düşük 7.15 , en yüksek 8.16 ve ortalama 7.71 olarak bulunmuştur. Sonuçlar kiraz için önerilen $6-6.5 \mathrm{pH}$ değerinden biraz

Çizelge 1. Toprakların bazı fiziksel ve kimyasal özellikleri

\begin{tabular}{|c|c|c|c|c|c|c|c|c|c|c|}
\hline \multirow{2}{*}{$\begin{array}{c}\text { Bahçe } \\
\text { no }\end{array}$} & \multirow{2}{*}{$\begin{array}{l}\text { Bahçe } \\
\text { sahibi }\end{array}$} & \multirow{2}{*}{$\begin{array}{l}\text { Derinlik } \\
(\mathrm{cm})\end{array}$} & \multirow[t]{2}{*}{ Bünye sınıfı } & \multicolumn{3}{|c|}{$(\%)$} & \multirow[t]{2}{*}{$\mathrm{pH}$} & \multicolumn{3}{|c|}{$(\%)$} \\
\hline & & & & Kil & Silt & Kum & & $\mathrm{CaCO}_{3}$ & Tuz & O.M \\
\hline \multirow[t]{2}{*}{1} & Mustafa Ersoy & $0-30$ & Kil & 55.7 & 17.3 & 27.9 & 7.41 & 6.79 & 0.11 & 2.93 \\
\hline & & $30-60$ & Kil & 60.8 & 13.1 & 26.2 & 7.95 & 9.29 & 0.10 & 1.44 \\
\hline \multirow[t]{2}{*}{2} & Mehmet Aydın & $0-30$ & Kumlu tın & 15.3 & 14.1 & 70.6 & 7.15 & 30.02 & 0.04 & 0.32 \\
\hline & & $30-60$ & Kumlu killi tın & 23.7 & 20.4 & 56.0 & 7.90 & 25.37 & 0.06 & 1.67 \\
\hline \multirow[t]{2}{*}{3} & Mehmet Aydın & $0-30$ & Kumlu killi tın & 23.6 & 12.1 & 64.2 & 7.96 & 15.69 & 0.06 & 1.98 \\
\hline & & $30-60$ & Kumlu killi tın & 21.7 & 20.4 & 58.0 & 8.08 & 16.80 & 0.06 & 1.56 \\
\hline \multirow[t]{2}{*}{4} & İsmail Topuz & $0-30$ & Kumlu killi tın & 23.8 & 25.6 & 50.6 & 7.88 & 16.05 & 0.11 & 2.98 \\
\hline & & $30-60$ & Kumlu killi tın & 21.6 & 21.4 & 57.0 & 7.47 & 17.26 & 0.06 & 1.42 \\
\hline \multirow[t]{2}{*}{5} & Atilla Teke & $0-30$ & Killi tın & 35.4 & 23.4 & 41.1 & 7.92 & 6.72 & 0.12 & 1.69 \\
\hline & & $30-60$ & Killi tın & 33.0 & 23.2 & 43.8 & 7.57 & 5.74 & 0.10 & 1.25 \\
\hline \multirow[t]{2}{*}{6} & Ahmet Çatar & $0-30$ & Killi tın & 30.8 & 29.5 & 39.7 & 7.50 & 16.79 & 0.07 & 2.31 \\
\hline & & $30-60$ & Kumlu killi tın & 26.5 & 27.4 & 46.0 & 8.02 & 16.72 & 0.08 & 1.61 \\
\hline \multirow[t]{2}{*}{7} & Hamza Ak & $0-30$ & Kumlu killi tın & 25.1 & 26.0 & 48.9 & 7.58 & 8.39 & 0.08 & 1.75 \\
\hline & & $30-60$ & Kumlu tın & 16.2 & 21.4 & 62.5 & 8.16 & 13.05 & 0.07 & 0.74 \\
\hline \multirow[t]{2}{*}{8} & Hasan Gümüş & $0-30$ & Killi tın & 27.4 & 28.3 & 44.3 & 8.01 & 28.75 & 0.09 & 1.86 \\
\hline & & $30-60$ & Tın & 22.0 & 29.0 & 48.9 & 8.12 & 33.23 & 0.07 & 0.53 \\
\hline \multirow[t]{2}{*}{9} & Osman İpek & $0-30$ & Kumlu killi tın & 27.1 & 23.7 & 49.2 & 7.65 & 12.59 & 0.10 & 1.31 \\
\hline & & $30-60$ & Tın & 20.7 & 32.4 & 47.0 & 7.63 & 21.48 & 0.08 & 0.41 \\
\hline \multirow[t]{2}{*}{10} & Hasan Dönmez & $0-30$ & Kil & 43.1 & 20.8 & 36.1 & 7.73 & 5.60 & 0.06 & 1.43 \\
\hline & & $30-60$ & Kil & 46.7 & 20.5 & 32.9 & 7.76 & 5.94 & 0.05 & 1.28 \\
\hline \multirow[t]{2}{*}{11} & Alper Kara & $0-30$ & Tın & 22.4 & 32.0 & 45.7 & 7.42 & 16.16 & 0.07 & 2.34 \\
\hline & & $30-60$ & Kumlu tın & 15.6 & 20.8 & 63.7 & 7.74 & 15.08 & 0.04 & 0.83 \\
\hline \multirow[t]{2}{*}{12} & Hüseyin Balıkçı & $0-30$ & Tın & 26.2 & 31.4 & 42.4 & 7.65 & 13.26 & 0.13 & 2.05 \\
\hline & & $30-60$ & Kumlu tın & 17.6 & 16.5 & 66.0 & 7.50 & 16.50 & 0.08 & 0.68 \\
\hline \multirow[t]{2}{*}{13} & Hasan Ünlü & $0-30$ & Killi tın & 30.8 & 29.8 & 39.3 & 7.45 & 1.54 & 0.10 & 2.01 \\
\hline & & $30-60$ & Killi tın & 28.8 & 26.7 & 44.5 & 7.22 & 1.40 & 0.12 & 1.28 \\
\hline \multirow[t]{5}{*}{14} & Ali Gayretli & $0-30$ & Killi tın & 31.1 & 25.7 & 43.2 & 7.73 & 3.63 & 0.13 & 1.54 \\
\hline & & $30-60$ & Killi tın & 31.3 & 24.8 & 44.0 & 7.81 & 6.42 & 0.13 & 1.50 \\
\hline & & \multicolumn{2}{|c|}{ En düşük } & 15.3 & 12.1 & 26.2 & 7.15 & 1.40 & 0.04 & 0.32 \\
\hline & & \multicolumn{2}{|c|}{ Ortalama } & 27.5 & 23.5 & 47.8 & 7.71 & 13.82 & 0.08 & 1.52 \\
\hline & & \multicolumn{2}{|c|}{ En yüksek } & 60.8 & 32.4 & 70.6 & 8.16 & 33.23 & 0.13 & 2.98 \\
\hline
\end{tabular}


yüksektir ve pH' nın yükseldiği topraklarda mikro element noksanlığı görülme olasılığı yüksektir (Reuter ve ark. 1997). Araştırma alanı topraklarının \%14' ü ağır \%57' si hafif ve \%29' u orta tekstür sınıfında topraklardır ve tüm sert çekirdekli meyvelerde olduğu gibi kiraz içinde uygun tekstüre sahiptir. Kireç bakımından incelendiğinde, toprakların sadece \%10' luk kısmının az kireçli olduğu, \%36' sının orta kireçli, \%46' sının fazla kireçli ve \%8' ininde çok fazla kireçli olduğu belirlenmiştir ve 30-60 cm'lik derinlikte genellikle kireç miktarı yüksek çıkmıştır. Araştırma alanı topraklarının tamamında tuz problemi yoktur. Organik madde açısından incelendiğinde ise toprakların \%21' inde organik madde çok az, \%57' sinde az ve \%22' sinde orta düzeyde bulunmuştur. Organik madde miktarının 0-30 cm toprak derinliğinde daha yüksek olduğu gözlenmektedir.

Toprakların bazı besin maddesi kapsamları: Kimyasal analizleri yapılan araştırma alanı topraklarının bitki besin maddesi içerikleri Lindsay ve Norvell (1969), FAO (1990), TOVEP (1991), Güneş ve ark. (1996)'ya göre Alpaslan ve ark. (1998)'in bildirdiği şekilde Çizelge 2' de verilmiş olan analiz sonuçları incelendiğinde; toprakların \%14' ü çok az, \%46' sı az, \%28' i yeterli düzeyde $N$ içermektedir. Sadece 4 No.lu bahçenin $0-30 \mathrm{~cm}$ toprak derinliğinde fazla miktarda $\mathrm{N}$ bulunmuştur. Topraklar $\mathrm{P}$ içerikleri bakımından incelendiğinde; \%14' ünde az, \%78' sinde yeterli, \%8' inde fazla miktarda $\mathrm{P}$ tespit edilmişdir. Araştırma alanının topraklarının $\mathrm{K}$ durumu ise sırasıyla $\% 54$ ' ünde az, \%39' unda yeterli, \%7' sinde ise fazla miktardadır. Toprakların hafif bünyeli oluşu $\mathrm{K}$ azlığına da bir işarettir. Topraklarda ortalama olarak $4020 \mathrm{mg} / \mathrm{kg}$ alınabilir $\mathrm{Ca}$ mevcut olup sınır değerler ile karşılaştırıldığında; toprakların yeter ve fazla miktarda $\mathrm{Ca}$ içerdiği ve eksikliğinin söz konusu olmadığı görülmektedir. Bitki besin maddelerinden Mg; bahçelerin \% 50' sinde yeterli durumda, \%32' sinde fazla durumda ve \%18' inde ise çok fazla durumdadır. Mg'un çok fazla olduğu topraklar tekstür yönünden incelendiğinde ağır bünyeli topraklar olduğu gözlenmektedir. Bir diğer besin elementi Na'un topraklarda yeter miktarda mevcut olduğu belirlenmiștir. Toprak örnekleri, mikro besin maddeleri açısından, Eyüboğlu ve ark. (1998)'nın Viets ve Lindsay (1973)'e göre bildirdikleri şekilde incelendiğinde, toprakların tamamının $\mathrm{Fe}$ içeriğinin, $\mathrm{Fe}$ için belirlenen $4.5 \mathrm{ppm}$ sınırının altında olduğu görülmekte olup ortalama olarak Fe miktarının 2.85 ppm olduğu belirlenmiştir. $\mathrm{Zn}$ ve $\mathrm{Cu}$ açısından toprak örneklerinin tamamında miktar kritik değerlerin üstünde olup, topraklarda ortalama olarak 1.81 $\mathrm{ppm} \mathrm{Zn}$ ve $0.75 \mathrm{ppm} \mathrm{Cu}$ bulunduğu belirlenmiştir. Örneklerin \%39' unda Mn, belirlenen 1.0 ppm sınır değerin altında bulunmuş olup, yetersiz düzeydedir. Örneklerin $\% 61$ ' inde ise $\mathrm{Mn}$ yeterli düzeydedir.

Çizelge 2. Toprakta bazı bitki besin maddesi kapsamları

\begin{tabular}{|c|c|c|c|c|c|c|c|c|c|c|c|}
\hline \multirow{2}{*}{$\begin{array}{c}\text { Bahçe } \\
\text { no }\end{array}$} & \multirow{2}{*}{$\begin{array}{c}\text { Derinlik } \\
(\mathrm{cm})\end{array}$} & $\%$ & \multirow{2}{*}{$\begin{array}{l}\mathrm{ppm} \\
\mathrm{P}\end{array}$} & \multicolumn{4}{|c|}{$\mathrm{ppm}$} & \multicolumn{4}{|c|}{$\mathrm{ppm}$} \\
\hline & & Total $\mathrm{N}$ & & $\mathrm{Ca}$ & $\mathrm{Mg}$ & $\mathrm{K}$ & $\mathrm{Na}$ & $\mathrm{Fe}$ & $\mathrm{Mn}$ & $\mathrm{Zn}$ & $\mathrm{Cu}$ \\
\hline 1 & $0-30$ & 0.17 & 25 & 4578 & 1442 & 628 & 48.4 & 2.33 & 1.55 & 1.55 & 0.78 \\
\hline & $30-60$ & 0.07 & 13 & 4026 & 1795 & 125 & 63.8 & 2.82 & 0.56 & 1.58 & 0.68 \\
\hline 2 & $0-30$ & 0.01 & 30 & 2792 & 272 & 55 & 19.8 & 3.36 & 2.96 & 1.53 & 0.71 \\
\hline & $30-60$ & 0.10 & 15 & 3828 & 402 & 129 & 19.8 & 2.78 & 4.63 & 1.75 & 0.62 \\
\hline 3 & $0-30$ & 0.13 & 42 & 3134 & 302 & 129 & 15.4 & 2.57 & 2.88 & 1.54 & 0.51 \\
\hline & $30-60$ & 0.09 & 21 & 3478 & 318 & 86 & 15.4 & 2.78 & 1.75 & 1.65 & 0.72 \\
\hline 4 & $0-30$ & 0.22 & 58 & 3412 & 454 & 288 & 15.4 & 3.10 & 4.23 & 1.86 & 0.62 \\
\hline & $30-60$ & 0.07 & 11 & 3092 & 360 & 144 & 15.4 & 2.36 & 1.34 & 1.64 & 0.62 \\
\hline 5 & $0-30$ & 0.10 & 22 & 4492 & 3261 & 168 & 19.8 & 3.04 & 0.22 & 1.95 & 0.76 \\
\hline & $30-60$ & 0.06 & 18 & 4176 & 3100 & 142 & 19.8 & 2.78 & 0.11 & 1.61 & 0.86 \\
\hline 6 & $0-30$ & 0.16 & 15 & 3518 & 964 & 183 & 19.8 & 3.28 & 0.21 & 1.59 & 0.74 \\
\hline & $30-60$ & 0.08 & 18 & 3746 & 386 & 105 & 19.8 & 3.02 & 1.1 & 1.77 & 1.04 \\
\hline 7 & $0-30$ & 0.09 & 23 & 5132 & 651 & 445 & 15.4 & 3.06 & 0.11 & 1.75 & 1.09 \\
\hline & $30-60$ & 0.03 & 15 & 4370 & 753 & 168 & 15.4 & 2.92 & 1.03 & 1.73 & 0.65 \\
\hline 8 & $0-30$ & 0.09 & 36 & 3958 & 340 & 105 & 15.4 & 3.14 & 0.31 & 1.78 & 0.63 \\
\hline & $30-60$ & 0.03 & 5 & 3742 & 292 & 63 & 15.4 & 2.92 & 0.10 & 1.98 & 0.62 \\
\hline 9 & $0-30$ & 0.07 & 13 & 4556 & 574 & 293 & 15.4 & 2.93 & 0.22 & 1.74 & 0.65 \\
\hline & $30-60$ & 0.02 & 6 & 4400 & 407 & 82 & 15.4 & 3.17 & 0.22 & 1.86 & 0.77 \\
\hline 10 & $0-30$ & 0.09 & 37 & 4522 & 1491 & 332 & 17.6 & 3.18 & 0.24 & 2.08 & 0.73 \\
\hline & $30-60$ & 0.07 & 8 & 3556 & 1444 & 281 & 17.6 & 3.87 & 0.47 & 1.88 & 1.06 \\
\hline 11 & $0-30$ & 0.16 & 25 & 3468 & 397 & 90 & 24.2 & 3.25 & 1.01 & 1.68 & 0.52 \\
\hline & $30-60$ & 0.06 & 11 & 3226 & 320 & 82 & 28.6 & 2.17 & 1.75 & 1.75 & 0.52 \\
\hline 12 & $0-30$ & 0.12 & 57 & 3556 & 391 & 160 & 24.2 & 2.50 & 1.01 & 2.09 & 0.63 \\
\hline & $30-60$ & 0.05 & 6 & 3280 & 319 & 82 & 19.8 & 2.88 & 1.75 & 1.85 & 0.72 \\
\hline 13 & $0-30$ & 0.11 & 22 & 4948 & 2505 & 203 & 30.8 & 2.36 & 7.52 & 2.04 & 0.75 \\
\hline & $30-60$ & 0.07 & 13 & 4882 & 1531 & 113 & 30.8 & 2.47 & 8.49 & 2.15 & 0.75 \\
\hline 14 & $0-30$ & 0.08 & 24 & 5364 & 736 & 101 & 19.8 & 1.96 & 4.78 & 2.07 & 0.98 \\
\hline & $30-60$ & 0.08 & 15 & 5358 & 739 & 70 & 30.8 & 2.82 & 3.47 & 2.39 & 1.52 \\
\hline En düşük & & 0.01 & 5 & 2792 & 272 & 55 & 15.4 & 1.96 & 0.10 & 1.53 & 0.51 \\
\hline Ortalama & & 0.08 & 23 & 4020 & 925 & 172 & 19.8 & 2.85 & 1.92 & 1.81 & 0.75 \\
\hline En yüksek & & 0.22 & 58 & 5364 & 3261 & 628 & 63.8 & 3.87 & 8.49 & 2.39 & 1.52 \\
\hline
\end{tabular}


Çizelge 3. Bitki örneklerinin bazı besin maddesi kapsamları

\begin{tabular}{|c|c|c|c|c|c|c|c|c|c|c|}
\hline \multirow{2}{*}{$\begin{array}{c}\text { Bahçe } \\
\text { no }\end{array}$} & \multicolumn{6}{|c|}{$\%$} & \multicolumn{4}{|c|}{$\mathrm{ppm}$} \\
\hline & $\mathrm{N}$ & $P$ & $\mathrm{~K}$ & $\mathrm{Ca}$ & $\mathrm{Mg}$ & $\mathrm{Na}$ & $\mathrm{Fe}$ & $\mathrm{Mn}$ & $\mathrm{Zn}$ & $\mathrm{Cu}$ \\
\hline 1 & 2.19 & 0.17 & 1.20 & 2.60 & 0.57 & 0.02 & 75 & 20 & 16 & 5.5 \\
\hline 2 & 1.98 & 0.19 & 1.45 & 2.15 & 0.35 & 0.02 & 106 & 49 & 16 & 6.5 \\
\hline 3 & 1.85 & 0.20 & 1.20 & 2.70 & 0.47 & 0.02 & 83 & 35 & 13 & 7.0 \\
\hline 4 & 2.67 & 0.20 & 0.58 & 1.56 & 0.35 & 0.02 & 88 & 49 & 15 & 8.0 \\
\hline 5 & 2.18 & 0.23 & 1.25 & 2.68 & 0.63 & 0.02 & 84 & 36 & 20 & 6.0 \\
\hline 6 & 2.13 & 0.19 & 1.20 & 1.70 & 0.33 & 0.02 & 76 & 37 & 13 & 5.0 \\
\hline 7 & 2.25 & 0.20 & 1.93 & 2.85 & 0.32 & 0.02 & 94 & 81 & 20 & 4.0 \\
\hline 8 & 1.57 & 0.12 & 1.10 & 2.11 & 0.32 & 0.02 & 59 & 33 & 13 & 4.0 \\
\hline 9 & 1.82 & 0.17 & 1.40 & 2.71 & 0.36 & 0.02 & 65 & 28 & 13 & 5.0 \\
\hline 10 & 1.97 & 0.18 & 1.25 & 2.73 & 0.53 & 0.02 & 63 & 36 & 15 & 2.5 \\
\hline 11 & 2.03 & 0.22 & 1.50 & 2.34 & 0.31 & 0.02 & 112 & 35 & 20 & 3.5 \\
\hline 12 & 2.10 & 0.18 & 1.00 & 2.43 & 0.32 & 0.02 & 118 & 22 & 21 & 4.0 \\
\hline 13 & 2.39 & 0.26 & 1.65 & 2.92 & 0.51 & 0.01 & 68 & 82 & 14 & 5.0 \\
\hline 14 & 2.89 & 0.21 & 1.35 & 2.87 & 0.40 & 0.02 & 84 & 92 & 14 & 6.5 \\
\hline
\end{tabular}

Bitki örneklerinin bazı bitki besin maddesi kapsamları: Araştırma alanında yetiştirilen kiraz yapraklarının, Çizelge 3'de besin maddesi kapsamları Jones ve ark. (1991)'nın bildirdiğine göre incelendiğinde, $\mathrm{N}$ açısından yaklaşık bütün bahçelerde bir noksanlık gözlenmemiş, sadece 8 No.lu bahçenin sınır değere yakın olduğu belirlenmiş, örneklerin $\% 50$ ' sinin $\mathrm{P}$ yönünden yeterli düzeyde olduğu saptanmış, \%50' sinin de noksan düzeyde $\mathrm{P}$ içerdiği belirlenmiştir. Yaprak örneklerinin $\mathrm{K}$ içeriği ise toprak analizleri ile uyumlu olarak yetersiz bulunup örneklerin sadece $\% 21$ ' inde yeterli düzeyde $\mathrm{K}$ olduğu belirlenmiştir. Örneklerin $\mathrm{Ca}$ miktarı toprak analizleri ile de uyum göstererek yeter düzeyde olup toprak analizleri ile uyum göstermektedir. Bir diğer makro besin maddesi $\mathrm{Mg}$ ise bütün örneklerde yeter miktarda olup bu besin elementide toprak analizleri ile uyumludur. Örneklerde Na, Reuter ve ark. (1997)' ye göre kiraz için incelendiğinde; yeterli düzeyde olduğu anlaşılmaktadır. Mikro besin maddeleri açısından yapraklar değerlendirildiğinde; örneklerin \%64'ünde Cu yeterli düzeyde olup, \%36'sında eksiktir. Yaprak örneklerinin \% 21'inde Fe yeterli düzeydedir. Toprak örneklerinde de olduğu gibi yaprak örneklerinin de $\mathrm{Fe}$ kapsamı yetersiz bulunmuştur. Yaprak örneklerinin \%36'sında Mn yeterli düzeyde, \%64'ünde noksan ve $\mathrm{Zn}$ ise örneklerin sadece $\% 28$ 'inde yeterli düzeyde, $\% 72$ ' sinde noksan düzeydedir.

\section{Sonuç ve Öneriler}

$\mathrm{Bu}$ araştırmadan elde edilen sonuçlar incelendiğinde; Eldivan yöresinde kiraz yetiştirilen toprakların \%57' si hafif, \%29'u orta ve \%14'ü ağır bünyeli ve pH' larının nötr den hafif alkaliye doğru değiştiği belirlenmiştir. Toprakların $\% 46$ 'sı fazla kireçli, \%36'sında orta düzeyde kireç mevcut olup ve \%57'sinin organik madde miktarı düşüktür.

Toprakların \%62'sinde az ve çok az N, \%74'ünde ise yeter ve fazla miktarda $P$ olduğu belirlenmiştir. $3,5,8$ ve 12 No.lu bahçelerde fazla miktarda $P$ belirlenmiş olması, bahçelerde aşırı gübrelemeden kaynaklanıyor olabilir. Potasyum açısından ise toprakların \%54'ünde yetersizlik saptanmıştır. Yaprak analiz sonuçlarında da örneklerin \%79'unda $\mathrm{K}$ yetersiz düzeyde bulunmuştur. $\mathrm{Ca}$ ve $\mathrm{Mg}$ açısından topraklarda ve bitki örneklerinde bir yetersizlik sorunu söz konusu değildir. Yaprak ve toprak örneklerinin mikro element durumlarının birlikte incelenmesiyle hem yaprak hem de toprakta $\mathrm{Fe}$ ve $\mathrm{Mn}^{\prime}$ in büyük oranda yetersiz olduğu tesbit edilmiştir. $\mathrm{Zn}$ ise topraklarda yeterli düzeyde olmasına rağmen yaprak örneklerinde yetersiz olduğu belirlenmiştir. Yaprak ve toprak örneklerinde ise $\mathrm{Cu}$ açısından bir noksanlık tespit edilmemiştir.

Kiraz tarımı yapılan bu bölgemizde, özellikle N,K,P gibi makro ve $\mathrm{Fe}, \mathrm{Mn}$ gibi mikro besin maddelerinin eksikliklerini gidermeye yönelik gübre kullanımının teşvik edilmesi ülkemiz ve yöre açısından önemli bir ihraç ürünü olan kirazın verim ve kalitesini yükseltecektir.

Yapılan korelasyon ve regrasyon analizi sonuçlarına göre; Toprakta bulunan $\mathrm{Ca}$ miktarı ile bitkide bulunan $\mathrm{Ca}$ arasında anlamlı bir korelasyon vardır $(p<0.05)$. Topraktaki $\mathrm{Ca}$ ile bitkideki $\mathrm{Ca}$ arasındaki regrasyon modelimiz şöyledir. Ca (bitki) $=-154.80+5.6610^{2} \mathrm{Ca}$ (toprak) şeklinde olup regrasyon katsayısı anlamlı saptanmıştır $(p<0.05)$. Buna göre bitkide bulunan $\mathrm{Ca}$ içeriğinin \%55'i topraktan alınan Ca ile açıklanabilir.

Toprakların $\mathrm{N}$ içerikleri ile bitki örneklerinin $\mathrm{N}$ içerikleri arasında da anlamlı bir korelasyon saptanmış olup $(p<0.05)$, topraktaki $\mathrm{N}$ ile bitkideki $\mathrm{N}$ arasındaki regrasyon modelimiz $\mathrm{N}$ (bitki) $=208.59-0.26 \mathrm{~N}$ (toprak) şeklindedir. Regrasyon katsayısı anlamlı bulunmuştur $(p<0.05)$. Bitkiden alınan $N^{\prime}$ deki değişkenin \%17'si topraktan alınan $\mathrm{N}$ ile açıklanabilir.

Topraktan alınan Mn ile bitkide bulunan $\mathrm{Mn}$ arasında anlamlı bir korelasyon tespit edilmiştir $(p<0.05)$. Topraktaki $\mathrm{Mn}$ ile bitkideki $\mathrm{Mn}$ arasındaki regrasyon modelimiz ise $\mathrm{Mn}$ (bitki) $=34.57+6.3410^{3} \mathrm{Mn}$ (toprak) şeklinde olup regrasyon katsayısı anlamlı olmuştur $(p<0.05)$. Bitkiden alınan Mn' deki değişkenin \%64'ü topraktan alınan Mn ile açıklanabilir.

\section{Kaynaklar}

Anonim 2002. Tarım İstatistikleri Özeti. Di̇E. Tarım İstatistikleri Şubesi. Ankara. 
Alpaslan M., A. Güneş ve A. İnal. 1998. Deneme Tekniği. Ankara Üniv. Ziraat Fak. Yayınları: 1501, Ders Kitabı: 455, Ankara.

Başar, H., A. Özgümüş ve A. V. Katkat. 1997. Bursa yöresinde yetiştirilen şeftali ağaçlarının azot, fosfor, potasyum, kalsiyum ve magnezyum ile beslenme durumlarının yaprak analizleri ile incelenmesi. TÜBITAK. Tr. J. of Agriculture and Forestry 21: 257-266.

Bozkurt, M. A., K. M. Çimrin ve S. Karaca. 2000. Aynı koşullarda yetiştirilen üç farklı elma çeşidinde beslenme durumlarının değerlendirilmesi. Ankara Üniv. Ziraat Fak. Tarım Bilimleri Dergisi 6 (4): 101-105.

Canözer, Ö., M. Çakır, G. Püskülcü ve Ü. Dikmelik. 1984. Ege Bölgesi Önemli Kiraz Çeşitlerinin Bitki Besin Element Durumları ve Toprak - Bitki İlişkileri. Tarım Orman ve Köyişleri Bakanlığı. Zeytincilik Araştırma Enstitüsü Müdürlüğü Yayınları. İzmir.

Eyüboğlu, F., N. Kurucu ve S. Talaz. 1998. Türkiye Topraklarının Bitkiye Yarayışlı Bazı Mikro Elementler (Fe, Cu, Zn, Mn) Bakımından Genel Durumu. T.C. Başbakanlık K.H.G.M. Toprak ve Gübre Araş. Enst. Müd. Ankara.

Eyüboğlu, F. 1999. Türkiye Topraklarının Verimlilik Durumu. T.C. Başbakanlık K.H.G.M. Toprak ve Gübre Araş. Enst. Yayınları. Gen. Yay. No:220.

FAO, 1990. Micronutrient, assesment at the country level : An international study. FAO Soils Bulletin 63. Rome

Güleryüz M., İ. Bolat, L. Pırlak, A. Eşitken ve S. Erişli. 1996. Erzincan'da Yetiştirilen Hasanbey Kayısı Çeşidinin Beslenme Düzeyinin Belirlenmesi. TÜBITAK. Tr. J. Agriculture and Forestry 20: 479-487

Güneş A., A.Inal ve M. Alpaslan. 1996. Effect of Salinty on Stomal Resistance, Proline, and Mineral Composition of Pepper. Journal of Plant Nutrition 19 (2): 389-396.

Jones Jr. J. B., B. Wolf and H. A. Mills. 1991. Plant Analysis Handbook. Micro-Macro Publishing Inc. USA.

Kacar, B. 1972. Bitki ve Toprağın Kimyasal Analizleri. II. Bitki Analizleri. Ankara Üniv. Ziraat Fak. Yayınları. No:453.
Kacar, B. 1994. Bitki ve Toprağın Kimyasal Analizleri. III. Toprak Analizleri. Ankara Üniv. Zıraat Fak. Eğitim Araştırma ve Geliştirme Vakfı Yayınları: 3, Ankara.

Köseoğlu, A. T. ve M. Acar. 1994. Uluborlu ve Senirkent (Isparta) Yörelerinde Yetiştirilen Kirazların Beslenme Durumlarının Belirlenmesi I. Makro Besin Elementleri. Tr. J. Agricultural and Forestry $18: 417-422$.

Köseoğlu, A. T. 1995. Uluborlu ve Senirkent (Isparta) Yörelerinde Yetiştirilen Kirazların Beslenme Durumlarının Belirlenmesi II. Mikro Besin Elementleri. Tr. J. Agricultural and Forestry 19: $349-353$.

Lindsay, W. L. and W. A. Norvel. 1969. Development of a DTPA Micronutrient Soil Test. Soil Sci. Am. Proc. 35: 600-602.

Reuter, D. J. and J. B. Robinson. 1997. Plant Analysis. An Interpretation Manual. Second Edition. CSIRO Land and Water. CSIRO Publishing. Australia.

Tarakçığlu , C., S. R. Yalçın, A. Bayrak, M. Küçük ve H. Karabacak. 2001. Ordu yöresinde yetiştirilen fındık bitkisinin (Corylus avellana L.) beslenme durumunun toprak ve yaprak analizleriyle belirlenmesi. Tarım Bilimleri Dergisi 9 (1): 13- 22.

Tovep, 1991. Türkiye Toprakları Verimlilik Envanteri. T.C.Tarım Orman ve Köyişleri Bakanlığı Köy Hizmetleri Gen. Müd.

Viets , F. G. and W. L. Lindsay. 1973. Testing soil for zinc, copper, manganese and iron. Soil Testing and Analysis. Ed: L.W. Walsh, J. D. Peaton. Soil Sci. Soc. America Inc. Madison. U.S.A.

\section{İletişim adresi:}

Mustafa BAŞARAN

Ankara Üniversitesi Çankırı Orman Fakültesi-Çankırı

Tel: 03762120519 